\title{
EMPLOYEE ENGAGEMENT OF FACULTIES IN MANAGEMENT INSTITUTES IN PUNE DURING COVID - 19 PANDEMIC
}

\section{DR. SONAL MAHAJAN, DR. SUNETRA GAITONDE \& UPENDRA LELE}

IndSearch Institute of Management Studies \& Research, Pune

ABSTRACT
In the present situation of COVID - 19 the employees and the workplaces across the globe have been facing challenges of
continuing their work during this pandemic. The educational institutions also had to explore various avenues for
enabling the faculty members to perform their duties even during the lockdown situation. Employee engagement,
therefore, has assumed great importance for ensuring that academic activities are conducted smoothly. Since the
employees have to work from home, use of technology for conducting lectures, examinations, and meetings have become
inevitable. This has posed some challenges to the educational institutions as well as faculty members. This exploratory
study has examined the innovative ways of engaging the faculty members in management institutes in Pune and the
challenges faced by them during the COVID - 19 situation from April 2020 to January 2021. It was found that more than
85\% of the time, the faculty members were busy not only in their regular activities like conducting lectures and
examinations, but they were also engaged in various other activities involving research, administration, and skill
development.
KEYWORDS: Employee Engagement, COVID - 19, challenges, Management Institutes.

Received: Aug 02, 2021; Accepted: Aug 20, 2021; Published: Aug 31, 2021; Paper Id.: IJHRMRDEC20216

\section{INTRODUCTION}

Today, COVID - 19 has disrupted the working of every business. As per the need of the hour, employees are asked to work from home, but this change has made the work environment difficult for the employees. Employees have found a lot of disturbing factors like managing household duties along with academic commitments, and lack of equipment and tools, (computer, webcam, internet connection etc.) while working from home which created job insecurity among the employees and could not focus on their work. Thus, it becomes necessary for employers to adhere to the new way of employee engagement as one of the important aspects of managing talent. This new way of working on employee engagement has triggered a large number of research and has made every employer come up with innovative and creative ways or effective ideas of engaging their employees to build resilience during the mayhem of this pandemic. Supporting employee engagement is nothing but managing talent indirectly by being committed together towards the organization and building satisfaction and motivation within the employees. Employee engagement is pivotal in organizations as an engaged employee is physically and mentally involved in his work role and feels extremely satisfied with his job. The engagement of employees in their work role leads to achieving the organizational goals and objectives further leading to effective business results.

\section{LITERATURE REVIEW}

In the current scenario, COVID - 19 has evolved as a pandemic in which most of the huge countries have suffered a lot with a health crisis and as an international economic threat. In this situation, the companies have gone 
completely remote for the first time. Due to the rapid growth of the COVID - 19 crisis the request for precaution includes keeping social and physical distancing for safety has made the world face many problems in varied fields. This has made the organizations to balance the onsite work and work from home. As a result of which the work-life and the personnel life has become more challenging to most of the employees.

Employee engagement is more challenging in this situation for employers. In the education field, most of the schools, training firms, institutes, colleges and universities have been impacted by this crisis. India being a developing country with diverse economic socio status, it was difficult to bring all the students on the same platform of virtual learning. At the same time, lectures were conducted with less study material available.

The main role of the teaching fraternity has played a varied role in this COVID - 19 situation to cover the students all over and conducted lectures, exams, seminars, training, etc to keep them intact with the educational materials and knowledge.

Employee engagement was a crucial task for most of the institutes, schools, universities. But still, the employers have kept the faculties in their roles by giving them timely training, seminars, workshops to cope up with the crisis and keep them engaged in this situation.

As a part of this, this study is mainly focused on the Management Institutes faculties employee engagement. The faculties have strived for the objective to keep the students engaged with various tools and methods of teaching. With which the faculties themselves have also been engaged in self-development by the means of Virtual training, Online workshops, Faculty Development Programme, etc.

This pandemic kept the faculty members of the institutes at home for their safety. So, everyone had to be at home and engage themselves in work by keeping themselves at home and at the same time also handle the household chores for everyone at home. Work from home (WFH) has been challenging for them as their family members were at home. The overall task of employee engagement for the faculty members has faced ups and downs in conducting lectures, scheduling virtual meetings, attending seminars, giving presentations, etc.

The challenges faced by the faculty members have played a crucial role as this situation of being remote from others and creating distance socially and physically has resulted in a lack of emotional and health crisis. The faculties who have the sources may have faced less challenges but the one's in remote areas within Pune have also faced difficulties in net connectivity, availability of resources, in the second half of the pandemic to travel to the institutes. Coping with the barriers and coming up with solutions, faculties have still managed to engage themselves within this COVID - 19 pandemic situation.

A report by the Institute of Employment Studies (2018) has stressed the importance of employee engagement in improving organizational performance. They have identified the nature and transparency of work undertaken by the employees as two of the seven important drivers of employee engagement. It is also mentioned that employee engagement in institutes of higher education is assuming growing importance due to several factors like increased competition and restrictions on government funding.

Regy J. and Malini D.H. (2017) have presented an empirical study on the current engagement level of staff in select higher educational institutes and colleges in South India on seven factors related to hygiene, policies, motivation, people, self, manager, and the organization. The results showed that a conducive work environment has a positive effect on 
employee engagement. The paper also stressed upon the need for employee engagement for retaining talent within the institution.

A paper published by Kumar P. (2021) presents V5 model of employee engagement during the COVID - 19 pandemic situation which suggests that HR managers should focus on five major elements of employee engagement, viz., value, variety, voice, vision, and virtue. The author has argued that redefining and reimplementing the employee engagement model using these elements will result in revitalizing the organization. This concept presented in this article is applicable to all organizations, which include educational institutions.

Channa N, Sangeeta (2020) have presented the employee engagement practices being followed by companies during COVID - 19 pandemic since employee engagement has assumed great importance during this period. Some of the employee engagement activities adopted by companies were virtual team meet-ups, weekly alignment online sessions, virtual learning and development, webinars with industry experts, online team building activities, and online family engagement practices. The authors also stated that the use of technology in establishing employee engagement was necessary for the growth of organizations.

According to Jack Welch, (2003) employee engagement means passion and emotional bonding of an employee with the organization and his/her work. He has given a brief description of the levels of engagement in which he first says that engaged employees are builders; who work with passion, they feel connected to work and the employer and they also drive innovative work techniques. Secondly, he stated that employees who are not engaged, concentrate more on tasks rather than goals and outcomes. Thirdly, according to Welch actively disengaged employees constantly interfere with others productivity.

Catteeuw, Frank, Johnson and Johnson (2009) opine that employee engagement is nothing but the employees building collaboration and trust, feeling valued and being satisfied with their jobs. According to them engaged employees remain loyal to the company and contribute to it through smart and effective ways thereby adding value to the organization which results in people flourishing and increasing productivity.

Pratima and Bhagirathi (2016) have studied that the success of the company is due to the impact of employee engagement with 6C's namely, Convey, Confidence, Credibility, Clarity, Carrier and Connect. These 6C's are used to improve employee engagement in manufacturing companies.

Osborne and Hammoud (2017) have stated in their research that employee engagement leads to effective communication in organizations which benefit in terms of rewards, recognition, empowering employees and building a bond between leaders and employees. It also utilizes the management's capability to leverage employee engagement strategies in organizations. Employee engagement also benefits the leaders through improved business practices, further encouraging the leaders to create leadership strategies to help raise employee engagement and job performance.

Baran and Barbara (2020) in their article mentioned the impact of two types of Management Methods on Employee Engagement, namely, people-oriented management and non-people-oriented management. According to them, people-oriented management plays a significant role in work engagement, whereas in non-people-oriented management employees are treated as a profit source where they need to be supervised constantly.

Adhitama and Riyanto (2020) through their research in the finance company stated that employees need to discover solutions to utilize all their abilities, knowledge and skills to make positive involvement and to accomplish the 
employee's and companies needs and wants. The study also encounters that employees should be adaptable working at home and be productive during the working hours.

Risley (2020) the study emphasizes the key elements of performance management and employee engagement with optimizing the performance to pursue best practices in this COVID - 19 situation. The author has discussed the concept of a growth mindset through learning and developing intelligence. the research also shares the five key areas where dual motivation plays a role: status, certainty, autonomy, relatedness and fairness. This theory is called as SCRAF model by Dr. Rock.

Meenakshi and Neha (2020) in their study argue that it is important to maintaining a good rapport with employees through effective communication and interaction. They also emphasize that employee engagement and retaining them is equally important to supporting the employees with technological know-how in this COVID - 19 situation. COVID - 19 has not only impacted the challenges in business organizations but also in personnel relationships. Thus, having a positive professional life enhances personal relationships and maintains harmony and peace in the organization in this situation.

\section{Research Objectives:}

- To identify the innovative ways of engaging faculty members of Management Institutes during COVID - 19 situation.

- $\quad$ To understand the types of challenges faced by faculty members during the COVID - 19 situation.

\section{Research Methodology}

The aim of this exploratory study was to understand the various employee engagement initiatives taken by the Management Institutes in Pune during the COVID - 19 pandemic and the challenges faced by faculty members in managing their academic commitments during this period.

A pilot study was conducted to understand the various activities that the faculty members were engaged in during the COVID - 19 lockdowns and post lockdown. The challenges faced by them were also listed during this pilot study. Based on these observations, a questionnaire was prepared and circulated to faculty members of Management Institutes in Pune, using convenience sampling. Total 78 responses were received and analyzed.

\section{Data Analysis}

The demographic characteristics of the respondents are presented in Figures 1, 2, and 3 below.

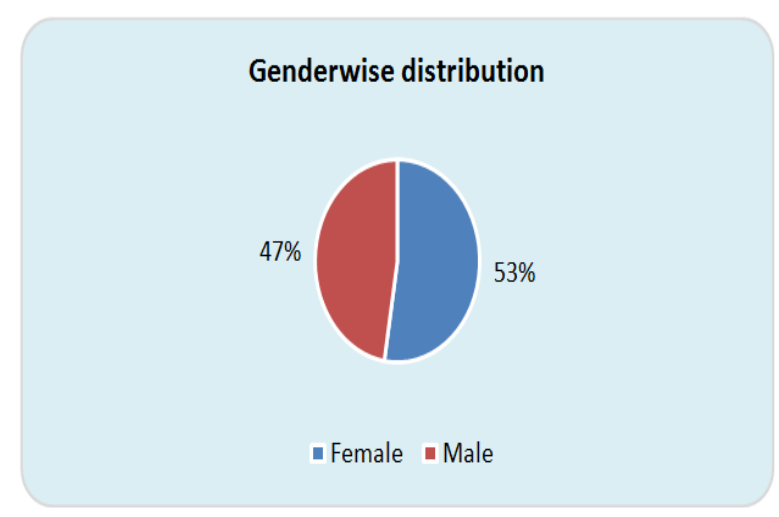

Figure 1: Gender Wise Distribution of Respondents 


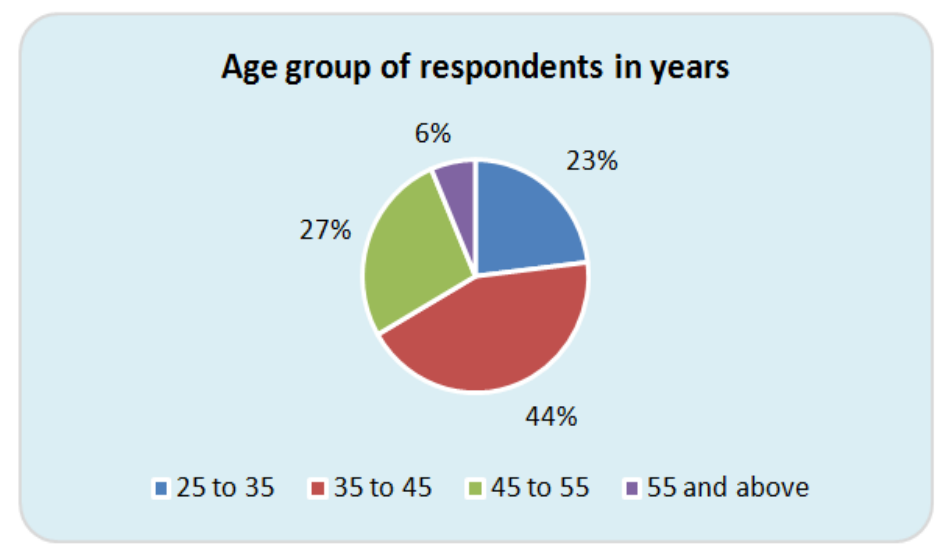

Figure 2: Age Wise Distribution of Respondents

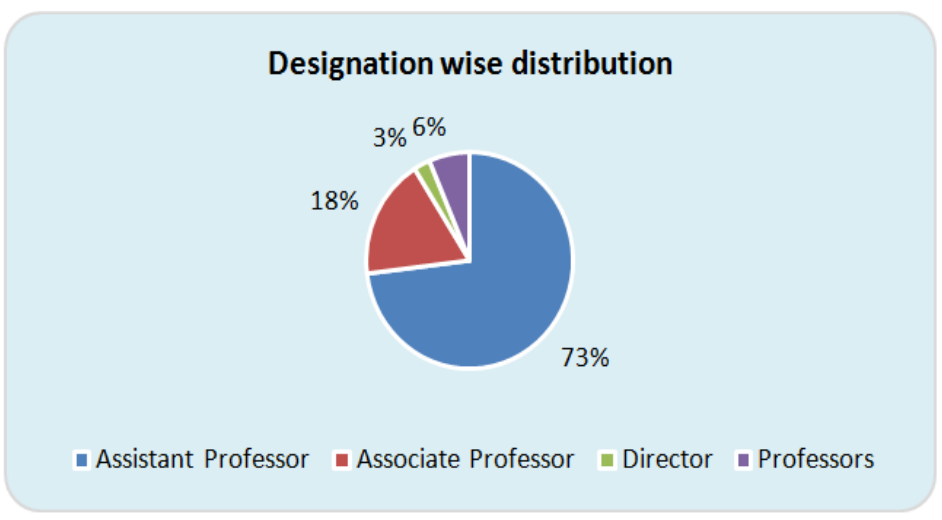

Figure 3: Designation Wise Distribution of Respondents

It may be observed that the respondents had almost equal distribution among males and females. Also, the majority of them belonged to the age group of 35 to 45 years and $73 \%$ were assistant professors. The average years of service of the respondents were 13 to 27 years. Since the time COVID - 19 lockdown started in April 2020, most faculty were working from home till the lockdown was lifted partially or fully in some cases. It was observed that the average number of days spent working from home during lockdown was 130, which is a little over 4 months.

\section{RESULTS}

\section{Activities Performed During Lockdown}

The Management institutes engaged the employees in various academic and research activities during and post COVID 19 lockdown period. The list of activities and percentage of faculty members engaged in them is given in Table 1 below.

Table 1: Activities Performed by Faculty during COVID - 19 Lockdown

\begin{tabular}{|l|c|c|}
\hline \multicolumn{1}{|c|}{ Activity } & Count & \% \\
\hline Conducting online lectures & 76 & $97.4 \%$ \\
\hline Conducting online examinations and assessments & 69 & $88.5 \%$ \\
\hline Attending faculty development programs (training, workshops) & 66 & $84.6 \%$ \\
\hline Attending online courses for skill development & 49 & $62.8 \%$ \\
\hline Attending faculty meetings online & 71 & $91.0 \%$ \\
\hline Writing research articles & 46 & $59.0 \%$ \\
\hline Conducting Webinars & 47 & $60.3 \%$ \\
\hline Attending Webinars & 67 & $85.9 \%$ \\
\hline Writing Blogs & 33 & $42.3 \%$ \\
\hline
\end{tabular}


It may be observed that the basic task of conducting lectures, examinations, and attending faculty meetings was uninterrupted even during lockdown. This is indicative of the capabilities of the Management institutions to quickly switch over from in-person mode to online mode of communication. It also indicates the availability and reliability of IT infrastructure in the Pune region, and the capability of faculty members to use the online teaching tools. Apart from the above activities, the faculty members were also engaged in several other activities like attending online courses and webinars, writing research articles and blogs to a considerable level. It shows that the faculty members were able to fulfill their responsibilities even during COVID - 19 lockdown situation.

\section{Challenges Faced by Faculty Members during the Work-From-Home Period}

The challenges faced by faculty members of Management institutes in Pune during the work-from-home period of COVID - 19 lockdown are presented in Table 2.a. below.

Table 2a: Challenges Faced by Faculty during Work-From-Home

\begin{tabular}{|l|c|c|}
\hline Challenges during work from home & Count & $\%$ \\
\hline Effectiveness of students' learning was doubtful & 61 & $78.2 \%$ \\
\hline Scheduling of household chores and academic commitments & 43 & $55.1 \%$ \\
\hline No internet or weak internet availability & 42 & $53.8 \%$ \\
\hline Lack of availability of Online teaching tools, & 28 & $35.9 \%$ \\
\hline Lack of knowhow of online teaching tools & 25 & $32.1 \%$ \\
\hline
\end{tabular}

The main challenge or concern expressed by the respondents was that they were uncertain about the effectiveness of students' learning during online lectures (78\% responses). This aspect needs further investigation to understand the reasons for such a concern expressed by the faculty members. Other reasons were the challenges in scheduling and prioritizing household responsibilities with academic commitments (55\%), and issues related to internet availability. Some faculty members also faced the issue of non-availability of online teaching tools (36\%) or lack of knowhow for use of such tools (32\%). However, the faculty members must have somehow managed to tackle these difficulties because as observed in Table $1,97 \%$ of the faculty members were able to conduct online lectures through some means.

\section{Challenges Faced by Faculty Members during Post Lock-Down Period}

After the lock-down was partially or fully lifted, the faculty members started attending their duties from the respective colleges. As mentioned before the lock-down period was around 4 months. The challenges faced by faculty members of Management institutes in Pune during the post lock-down period of COVID - 19 are presented in Table 2.b. below.

\section{Table 2b: Challenges Faced by Faculty during Post Lock-Down Period}

\begin{tabular}{|l|c|c|}
\hline Challenges during post lock-down period & Count & \% \\
\hline Effectiveness of students' learning was doubtful & 48 & $61.5 \%$ \\
\hline Availability of food and beverages nearby & 37 & $47.4 \%$ \\
\hline Maintaining self health care and sanitization & 57 & $73.1 \%$ \\
\hline Getting travel permission to come to the college & 17 & $21.8 \%$ \\
\hline Non-availability of public transport & 16 & $20.5 \%$ \\
\hline Limited availability of infrastructure (e.g. internet enabled classrooms) & 21 & $26.9 \%$ \\
\hline
\end{tabular}

The main challenge during the post lock-down period was related to maintain self-healthcare and sanitization $(73 \%$ responses). It was also observed that even during post lock-down period there were concerns effectiveness of students' 
learning (62\% responses). This is because even if faculty members started attending the college, the mode of teaching was still online. The third challenge was the availability of food and beverages because most of the food supply stores and restaurants were closed or were open for a limited duration during lock-down. Other challenges included the nonavailability of public transport, getting travel permissions, and limited infrastructure availability.

\section{Scope for Future Research}

The study shows that one of the major challenges with online teaching/learning is that the effectiveness of students' learning is doubtful. The faculty members found it difficult to ensure attentiveness of students and to gauge the extent of learning achieved by the students. This observation calls for further research on how to make online learning more effective in future.

\section{CONCLUSIONS}

It was found that more than $85 \%$ of the time, the faculty members were busy not only in their regular activities like conducting lectures and examinations, but they were also engaged in various other activities involving research, administration, and skill development. One of the major challenges and concerns of the faculty was ensuring the effectiveness of students' learning in online mode. Other challenges included maintaining self-health care and sanitization, and scheduling household chores along with academic commitments.

\section{REFERENCES}

1. Blog Report (2018), Employee engagement in the higher education sector: An Evidence Review, Institute of Employment Studies, Extracted from https://blogs.shu.ac.uk/hallamleaders/files/2018/01/employee_engagement_in_the_he_sector__evidence_review.pdf

2. Regy J., Malini D.H. (2017). EMPLOYEE ENGAGEMENT OF FACULTIES IN SELECT HIGHER EDUCATIONAL INSTITUTES IN SOUTH INDIA. International Journal of Advanced Research and Innovative Ideas in Education, 3, 1.

3. Kumar, P. (2021). V-5 Model of Employee Engagement During COVID - 19 and Post Lockdown. Vision, 0972262920980878.

4. Channa C, Snageeta (2020). Employee engagement practices during COVID - 19 lockdown. Journal of Public Affairs, https://doi.org/10.1002/pa.2508

5. Catteeuw, Frank; Johnson and Johnson, Flynn, Eileen; Vonderhorst, James (2007), "Employee Engagement: Boosting Productivity in Turbulent Times", Organization Development Journal; Chesterland Vol. 25, Iss. 2, (Summer 2007): P151P157.

6. Schrita Osborne and Mohamad S. Hammoud (2017), "Effective Employee Engagement in the Workplace", International Journal of Applied Management and Technology 2017, Volume 16, Issue 1, Pages 50-67, DOI:10.5590/IJAMT.2017.16.1.04

7. Dr. Pratima Sarangi and Dr. Bhagirathi Nayak (2016), "Employee Engagement and its Impact on Organizational Success - A study in manufacturing company, India" IOSR Journal of Business and Management (IOSR-JBM) e-ISSN: 2278-487X, pISSN: 2319-7668. Volume 18, Issue 4. Ver. I (Apr. 2016), PP 52-57.

8. Matgorzata Baran and Barbara Sypniewska, Article: "The Impact of Management Methods on Employee Engagement" Sustainability 2020, Published: 6 January 2020 12, 426; doi:10.3390/su12010426.

9. Julyan Adhitama and Setyo Riyanto (2020), "Maintaining Employee Engagement and Employee Performance during COVID 19 Pandemic at PT Koexim Mandiri Finance" Quest Journals Journal of Research in Business and Management Volume 8 Issue 3 (2020) pp: 06-10. 
10. Carine Risley (2020), "Maintaining Performance and Employee Engagement During the COVID - 19 Pandemic", JOURNAL OF LIBRARY ADMINISTRATION 2020, VOL. 60, NO. 6, 653-659., https://doi.org/10.1080/01930826.2020.1773716.

11. Meenakshi Kaushik and Neha Guleria (2020), "EMPLOYEE RELATIONS AND ENGAGEMENT DURING COVID - 19", Article · July 2020, Sparkling International Journal of Multidisciplinary Research Studies, A Quarterly Peer Reviewed/Refereed Multidisciplinary Journal Vol.3, Issue.2, April-June 2020.

12. Catteeuw F, Flynn E, Vonderhorst J (2007), 'Employee engagement: boosting productivity in turbulent times', Organization Development Journal, 25 (2), 151- 157.

13. Naidu, Jyoti. "Curbing staff turnover through employee engagement in the retail sector of Nagpur." International Journal of Human Resource Management and Research (IJHRMR) 6.3 (2016): 29-40.

14. Kanwar, Dipti, and Jyoti Jain. "An Empirical Study on Practice of Employee Engagement Activities in Hospitality Industry." International Journal of Human Resource Management and Research (IJHRMR) 8 (2018): 131-138.

15. Shailashri, V. T., Surekha Shenoy, and Suresh Kumar. "Employee Engagement in the Insurance Sector In Mangalore City of Dakshina Kannada." International Journal of Human Resource Management and Research (IJHRMR) 8 (2018): 35-40.

16. Chandel, P. R. E. R. N. A. "The Evolution of Employee Engagement: A Unique Construct." International Journal of Human Resource Management and Research (IJHRMR) 8.6 (2018): 199-216. 